\title{
Algumas variedades interessantes de mandioca (Manihot esculenta Crantz) da Amazônia (*)
}

\author{
D. B. Arkcoll ("*)
}

\section{Resumo}

Durante os três últimos anos, foram coletadas mais de 150 variedades de mandioca entre os índios e pequenos agricultores. Experimentos preliminares já identificaram algumas com caracteristicas interessantes. 1 - I M 171, uma variedade amarela com 3,2 mg caroteno/100 g de raiz. 2 - I M 097 capaz de render mais de $5 \mathrm{~kg}$ de $\mathrm{raiz} / \mathrm{m}^{2} /$ ano quando fertilizada em latossolo amarelo. $3-1 \mathrm{M} 159$ capaz de render $7 \mathrm{~kg}$ de $\mathrm{raiz} / \mathrm{m}^{2} \mathrm{em}$ apenas sete meses em várzea fértil. -4 I M $176 \mathrm{com}$ alguma tolerância à podridăo de raiz (Phy. tophthora drechsleri).

\section{INTRODUÇÃO}

A rnandioca (Manihot esculenta Crantz) é alimento básico da maioria das tribos indigenas e pequenos agricultores da região Amazônica. Todos possuem diversas variedades que, geralmente, passam de pai para filho e quase sempre levam a fama de ser as melhores da regiăo. Em alguns casos, variedades diferentes possuem o mesmo nome e, em outros, uma mesma variedade pode ter nomes diferentes, em lugares diferentes.

Experimentos realizados em Belém mostram grande número de variedades e seu potencial (Albuquerque, 1969). Algumas dessas variedades e outras que montam a mais de 150 , colecionacias nas tribos indígenas e de pequenos agricultores, formam a base da coleção do INPA.

E surpreendente observar que a maioria dos pequenos agricultores que habita a várzea fértil cultiva a mandioca em sistema de agricultura migratória nas terras firmes pobres próximas. Albuquerque (1969) reporta ao alto rendimento (35 t/ha em 4 meses) em terra de várzea. Realizaram-se então, alguns experimentos para examinar seu potencial e identifi. car seus problemas.
Compararam-se, no presente trabalho, al. gumas das variedades comumente reconheci. das como as melhores da regiăo de Manaus.

\section{MATERIAIS E MÉtodos}

Utilizaram-se manivas de $20 \mathrm{~cm}$ de material de 12-18 meses, as quais foram tratadas com fungicida (Orthocide) e inseticida (Diazinon 60 E) (Lozano et al., 1978 \& Toro et al., 1978). Estas foram plantadas horizontalmente em parcelas de $6 \times 6$ plantas e espaçamentos de $1 \times 1 \mathrm{~m}$ em experimentos com 3 a 6 repetições. Dezesseis p!antas foram colhidas por parcela 12 meses depois, na terra firme e 7 a 8 meses depois, na várzea.

EXPERIMENTO 1 - Arou-se uma área de latossolo amarelo mecanicamente desmatada dois anos antes. Esta recebeu $2 \mathrm{t}$ de calcário/ha e $200 \mathrm{~kg} \mathrm{P} \mathrm{O}_{5} / \mathrm{ha}$ como supertríplice de fosfato. Aplicaram-se $100 \mathrm{~kg} \mathrm{~N} / \mathrm{ha}$ e $200 \mathrm{~kg}$ $\mathrm{K}_{2} \mathrm{O}$ na forma de uréia e $\mathrm{KCl}$, três semanas após o plantio em dezembro.

EXPERIMENTO 2 - Compararam-se três variedades num experimento intercalado com frutíferas e espaçamento de $5 \mathrm{~m}$. Estas foram plantadas em fila dupla com $1 \mathrm{~m}$ de largura e a $2 \mathrm{~m}$ das árvores, dois meses após a queima da floresta. Colheram-se 6 blocos de $10 \mathrm{me}$ tros de comprimento depois de 12 meses.

EXPERIMENTOS 3 E 4 - Os ensaios da varicdade de várzea foram plantados com a baixa das águas em setembro e colhidos, 7 meses depois.

EXPERIMENTO 5 - Colheram-se amostras de 10 plantas cada uma de 3 partes do terreno de pequenos agricultores para dar uma idéia do rendimento potencial das diversas variedades.

1* ( - Apresentado no 1.0 Congresso Brasileiro de Mandioca, Salvador, 1979.

(*) - Instituto Nacional de Pesquisas da Amazônia, Manaus. 
EXPERIMENTO 6 - Tentou-se controlar a podridão da raiz na várzea, fazendo-se plantaçōes em camalhôes de 1 metro de distância e de $30 \mathrm{~cm}$ de altura, puiverizando-se mensalmente com os fungicidas sistêmicos Benlate e Dinamal - M 45 e selecionando-se para resistência e tolerância varietal. O efeito do espaçamento, idade de colheita e fertilizante também foram examinados. Utilizaram-se $50 \mathrm{~N}$, $100 \mathrm{P}_{2} \mathrm{O}_{\mathrm{s}}, 100 \mathrm{~K}_{2} \mathrm{O}$ ou $50 \mathrm{t}$ de esterco de galinha/ ha. No experimento do espaçamento, as plantas estavam a $0,8 \times 0,8 \mathrm{~m}, 1,0 \times 0,8 \mathrm{~m}, 1,0 \times$ $1,0 \mathrm{~m}$ e $1,2 \times 1,0 \mathrm{~m}$ de distância em parcelas quadradas replicadas de $6 \times 6 \mathrm{~m}$. Mediu-se o rendimento de 6 a 9 meses nas parcelas de idade.

Todos os resultados foram reduzidos a rendimento $/ \mathrm{m}^{2}$ para facilitar a comparação e a conversão de $t / h a$.

\section{RESUltados E Discussão}

CONTEÚdo DE CAROTENO: A seleção de variedades pelo conteúdo de caroteno foi relatada em outro trabalho (Arkcoll \& Marinho, 1980). A variedade IM 171 apresentou os maiores niveis com $3,2 \mathrm{mg} / 100 \mathrm{~g}$ de raiz e $2,01 \mathrm{mg} /$ $100 \mathrm{~g}$ de farinha.

EXPERIMENTOS EM LATOSSOLO (Q.1 e 2): Duas variedades 097 e 067 renderam mais de $1,5 \mathrm{~kg} / \mathrm{m}^{2}$ neste solo pobre sem fertilizantes (Quadro 1). A maioria das outras variedades rendeu aproximadamente $1,0 \mathrm{~kg} / \mathrm{m}^{2}$. As diferenças de rendimento foram, em grande parte, eliminadas, acrescentando-se fertilizantes. A variedade IM 097 rendeu $5,2 \mathrm{~kg} / \mathrm{m}^{2}$ enquanto que a maioria das variedades restantes rendeu entre $3-3,5 \mathrm{~kg} / \mathrm{m}^{2}$. A superioridade desta variedade de pequeno porte também foi mostrada no experimento intercalado com frutíferas, a qual rendeu $3,85 \mathrm{~kg} / \mathrm{m}^{2}$ sem fertilizantes (Quadro 2). Estes ótimos resultados deveramse em parte, à utilização de nutrientes na cinza, após a queima da floresta e em parte ao efeito da tordadeira dupla alcançado no plantio de fileiras de $4 \mathrm{~m}$ de distância. Desta maneira. a mandioca não compete seriamente com as árvores no primeiro ano mas fornece um rendimento equivalente a $1,54 \mathrm{~kg} / \mathrm{m}^{2}$ sobre o total da área e auxilia no controle da erosão e da
QUADRO 1 - 0 rendimento médio de 10 variedades de mandioca com e sem adubo num lą̧ossoio Amarelo.

\begin{tabular}{|c|c|c|c|c|c|}
\hline \multirow{2}{*}{\multicolumn{3}{|c|}{ Variedade }} & \multicolumn{3}{|c|}{ Rendimento $\mathrm{Kg} \mathrm{raiz} / \mathrm{m}^{2}$} \\
\hline & & & SEM & ADUBO & COM ADUBO \\
\hline \multicolumn{3}{|r|}{ I M. 084} & & 0.72 & 1.93 \\
\hline & & 104 & & 0.78 & 2.99 \\
\hline & & 119 & & 0.96 & 3.10 \\
\hline & & 129 & & 1.03 & 2.90 \\
\hline & & 139 & & 1.08 & 3.12 \\
\hline & & 085 & & 1.09 & 3.26 \\
\hline & & 136 & & 1. 18 & 3.55 \\
\hline & & 106 & & 1.28 & 3.43 \\
\hline & & 097 & & 1.59 & 5.22 \\
\hline & & 057 & & 1.64 & 3. 47 \\
\hline $5 \%$ & Tukey & D.M.S. & & 0.58 & 0.45 \\
\hline
\end{tabular}

QUADRO 2 - O rendimento médio de 3 variedades intercaladas com frutíferas depois da queima num Latossolo Amarelo.

\begin{tabular}{cc}
\hline Variedade & Rendimento médio $\mathrm{kg} \mathrm{raiz} / \mathrm{m}^{2}$ \\
\hline 139 & 1.47 \\
084 & 2.58 \\
097 & 3.85 \\
$5 \%$ Tukey D.M.S. & 0.44 \\
\hline
\end{tabular}

erva daninha. Parece importante estudarem-se os requisitos exatos de fertilizantes dessa variedade promissora.

EXPERIMENTOS NA VÁRZEA ALTA: Em 1978, perderam-se muitas raízes face à podridão (Phytophthora dreschsleri) (Figueiredo \& Albuquerque, 1970; Lozano \& Booth, 1978), nos experimentos 3 e 4 em diferentes campos. Apesar de esta ocorrência ter complicado consideravelmente os resultados, foi possível observar a existência de tolerância em algumas variedades. Grande parte das melhores variedades do experimento de terra-firme apresentou alto índice de crescimento superior, freqüentemente, a 4 metros de altura. Muitas delas apodreceram e tombaram sem produçăo alguma. A podridão atacou todas as variedades em algumas partes dos campos. Algumas parcelas foram severamente atacadas e outras não foram atingidas. Parece não haver ligação com as partes baixas desse campo. Os ataques ocorreram depois de 6 meses, geralmente quando as raízes já estavam bem formadas. Isto coincide com solos úmidos das chuvas 
QUADRO $3-0$ rendimento de diversas variedades na várzea de Caldeirão - 1978.

\begin{tabular}{|c|c|c|c|c|}
\hline \multirow{2}{*}{ Varledade } & \multicolumn{3}{|c|}{ Rendimento total $\mathrm{kg} / \mathrm{m}^{2}$} & \multirow{2}{*}{ Média } \\
\hline & 1 & 2 & 3 & \\
\hline I M 139 & $0.84 \cdots$ & $1.34^{*}$ & $1.97^{\circ}$ & 1.38 \\
\hline 096 & $0.93 \cdots$ & $2.81^{\bullet}$ & $1.75 \cdots$ & 1.83 \\
\hline 175 & 2.68 & $1.25^{*}$ & 2.15 & 2.03 \\
\hline 119 & $0.00 \cdots$ & $2.31^{*}$ & $1.15 \cdots$ & (1.73) \\
\hline 117 & 2.37 & $2.21^{*}$ & $1.81^{\bullet}$ & 2.13 \\
\hline 129 & $0 * \cdots$ & $0 \cdots \cdots$ & $0 \cdots$ & 0 \\
\hline 084 & $0 \cdots$ & $0 \cdots \cdots$ & $0 \cdots *$ & 0 \\
\hline 103 & $0 \cdots$ & $0 \cdots \cdots$ & $0 \cdots$ & 0 \\
\hline 097 & $0 \cdots \cdots$ & $0 \cdots \cdots$ & $0 * * * *$ & 0 \\
\hline 085 & $0 \cdots \cdots$ & $0 \cdots \cdots$ & $0 \cdots \cdots$ & 0 \\
\hline
\end{tabular}

PERDAS CAUSADAS PELA PODRIDÃo

$*=0-25 \% ; * *=25-50 ; \cdots=50-75 ; \cdots * *=75-100$.

crescentes e com a subida das águas que por fim ditam as épocas de colheita da várzea. As partes aéreas da planta raramente apresentaram sinal de ataque, mas a doença contribui para o tombamento de algumas parcelas.

Algumas parcelas renderam perto de 30 $t /$ ha ou seja 2 ou 3 vezes o rendimento daquelas parcelas tipicas de terra firme em metade do tempo. Colecionaram-se diversas variedades de bom crescimento na várzea para experimentos futuros. Sentiu-se que muitos dos pequenos agricultores, infelizmente, tinham selecionado variedades de alto rendimento/planta (até $17 \mathrm{~kg}$ ) quando plantadas a 2 metros de distância. Isso faz sentido em áreas, onde não há escassez de terra pois se necessita de menes esforço para plantar e colher. Uma variedade (IM 159), no entanto, produziu rendimento excepcional de $6,5 \mathrm{~kg} / \mathrm{m}^{2}$ e em uma área do campo, mais de $7,0 \mathrm{~kg} / \mathrm{m}^{2}$. (Quadro 5).

Os agricultores toleravam uma certa quantidade de podridão e tinham baixa perda em depósitos aluviais novos, arenosos e suficientemente inclinados para boa drenagem.

Os ataques de podridão novamente causaram problemas no experimento 6 , levando a uma perda de $25 \%$; assim, um rendimento de mais de $40 \mathrm{t} /$ ha foi reduzido a $30 \mathrm{t} / \mathrm{ha}$, sendo, mesmo assim, considerado bom pelos agricultores na várzea. Peln fato de os ataques ocorrerem na planta madura, só foram citados os rendimentos das plantas sadias. Isto permite a recuperação de informações mais úteis e confiáveis dos experimentos. A variedade IM 176 rendeu, consistentemente, mais de $2,5 \mathrm{~kg} / \mathrm{m}^{2}$ em ambos os experimentos 4 e 6 e parece ter mais tolerância à podridão do que a maioria das outras variedades. Nem os camalhö̉es nem os fungicidas reduziram os ataques de podridão. Mas a que não recebeu tratamento com fungicida apresentou baixo rendimento, dado um ataque de Mancha Marrom (Cercospora henningsii) .

A superioridade da variedade I M 159 fol confirmada. Seu rendimento foi consistentemente $4 \mathrm{~kg} / \mathrm{m}^{2}$ comparado a 2,5 a 3,4 para as outras variedades. Este rendimento estava consideravelmente abaixo do potencial mostrado no campo de coleção por várias razões: as manivas da colheita anterior foram armaze. nadas por 3 meses de maio até a época do plantio em fins de agosto, por causa da cheia e provavelmente perderam o vigor; as ervas daninhas foram controladas manualmente 3 vezes, o que provou ser insuficiente num solo tão fértil; o solo estava bem mais pesado apre-

QUADRO $4-0$ rendimento de diversas variedades na várzea de Ariaú - 1978.

\begin{tabular}{|c|c|c|c|c|c|c|c|}
\hline \multirow{2}{*}{ Variedade } & \multicolumn{6}{|c|}{ Rendimento total $\mathrm{kg} / \mathrm{m}^{2}$} & \multirow{2}{*}{ Média } \\
\hline & \multicolumn{2}{|c|}{1} & \multicolumn{2}{|c|}{2} & \multicolumn{2}{|l|}{3} & \\
\hline I M 139 & 0.59 & $\cdots$ & 1.84 & * & 1.53 & * & 1. 32 \\
\hline 079 & 1.00 & * & 0.84 & ** & 0.00 & $* * *$ & $(0.92)$ \\
\hline $68 \mathrm{~A}$ & 1.00 & $\cdots$ & 1.41 & $\cdots$ & 2.06 & & 1.49 \\
\hline 176 & 2.69 & • & 2.63 & & 2.41 & & 2.58 \\
\hline 078 & 0.00 & $\cdots$ & 0.00 & $\cdots$ & 0.00 & $\cdots$ & 000 \\
\hline
\end{tabular}

- \% Podridắo como no Quadro 3

QUADRO 5 - Os melhores rendimentos das variedades dos campos de pequenos produtores.

Variedade Rendimento médio $\mathrm{kg} / \mathrm{m}^{2}$ Desvio padrão

\begin{tabular}{lll}
\hline I M 158 & 3.97 & 0.54 \\
157 & 3.33 & 0.31 \\
$159(1)$ & 6.50 & 0.42 \\
$159(2)$ & 5.40 & 0.25 \\
085 & 3.18 & 0.36 \\
175 & 3.41 & 0.42 \\
\hline
\end{tabular}

$(1,2)$ Compos diferentes 
sentando $4 \%$ de areia, $66 \%$ silte $30 \%$ de argila comparado a 34,50 e $16 \%$ no campo de coleção.

Esta variedade cresce, geralmente, até uma altura de 2 metros e apresenta poucos galhos até 8 meses.

O esterco não aumenta o rendimento, apesar de ter-se observado um pequeno aumento com adubo face, provavelmente, ao $\mathrm{N}$ adicio. nado que é baixo nos solos aluviais lavados.

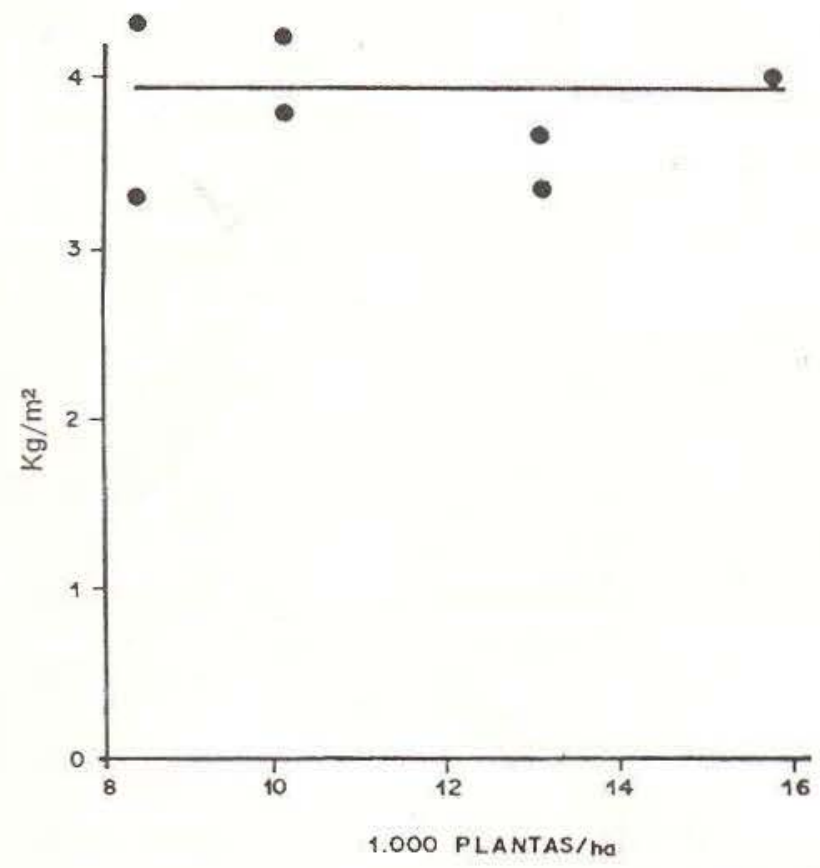

Fig. 1 - $O$ efeito de espaçamento sobre o rendimento de IM 159

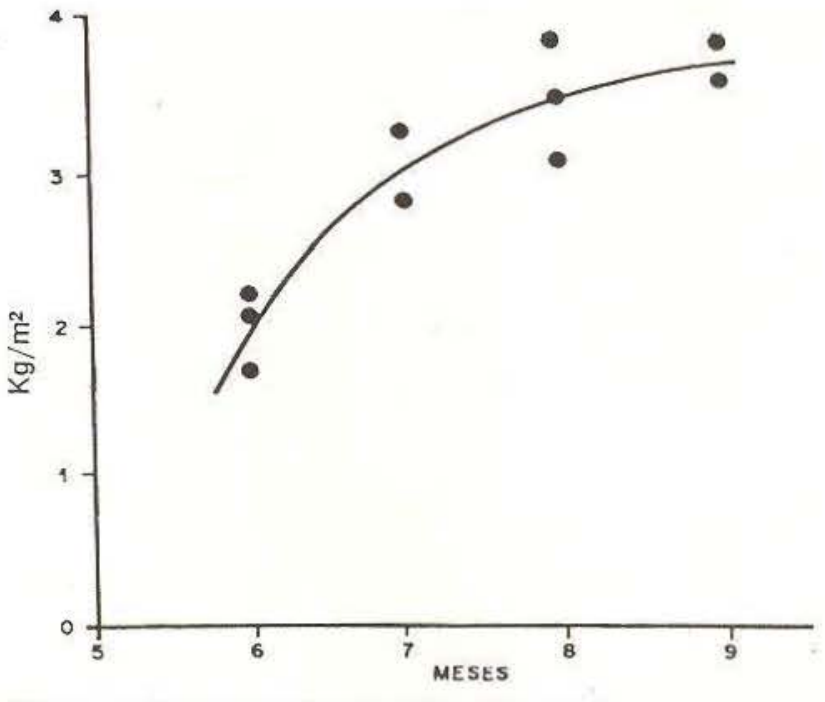

Fig. 2 - Rendimento de IM $158 \mathrm{com}$ idade

Os rendimentos não foram atingidos pelos espaçamentos empregados (Fig. 1) e nivelamse, depois de 7 meses de crescimento na variedade IM 158 (Fig. 2). Oito meses é, apro. ximadamente, o tempo máximo disponível, na área dos experimentos. Uma enchente baixa permitiu uma colheita, após 9 meses em 1979.

Fez-se farinha das duas melhores variedades 1 M 097 e 159, rendendo 32 e $31 \%$ de peso da raiz original. O tamanho da raiz e a facilidade em descascá-la são tão importantes como critério de seleção como o conteúdo de amido, pois pode haver perda de 5 a $25 \%$ no descascamento. Algumas dessas variedades precoces, como a I M 158 e a 159 produzem raízes grandes com cascas finas e dizem tornar-se aguadas, depois de 8 meses.

QUADRO 6 - O rendimento de diversas variedades na várzea de Ariaú-1979. Rendimento de plantas sadias $\mathrm{kg} / \mathrm{m}^{2}$.

\begin{tabular}{|c|c|c|c|c|c|}
\hline Variedade & Tratamento & 1 & 2 & 3 & Média \\
\hline I M 176 & Normal & 3.21 & $2.81^{\circ}$ & 3.19 & 3.07 \\
\hline 158 & - & $3.00^{\circ}$ & $3.78^{\circ}$ & 3.40 & 3.40 \\
\hline 083 & - & $2.63^{\circ}$ & $\ldots$ & $\ldots$ & 2.68 \\
\hline 085 & - & 2.00 & $3.50 \cdots$ & $2.13^{\circ}$ & 2.54 \\
\hline 175 & " & - & - & 2.28 & 2.28 \\
\hline 159 & " & $3.79^{\circ}$ & $4.20^{\circ}$ & $\cdots$ & 4.00 \\
\hline 159 & s/fungicida & $3.00^{\circ}$ & 3.00 & 2.75 & 2.92 \\
\hline 159 & + camalhōes & 4.67 & $3.53^{\circ}$ & $\cdots$ & 4.09 \\
\hline 159 & + NPK & $5.00 \cdots$ & $4.66 \cdots$ & $4.15^{\circ}$ & 4.60 \\
\hline 159 & " esterco & .. & $3.44^{\bullet}$ & 4.78 & 4.11 \\
\hline
\end{tabular}

- \% Podridōo como no Quadro 3 
Para melhorar o aproveitamento desse po. tencial para Mandioca na várzea estamos pro curando variedades com resistência à podridão de raiz, como, por exemplo, Cedinha e Osso duro, originárias da Paraiba (Lopes, et al., 1978) para cruzamento com IM 159. Entretanto, tenho as seguintes recomendaçōes:

1. Plantio da variedade I $\mathrm{M}-159$, em uma pequena área fértil da terra firme, em janeiro/fevereiro, de modo que se te. nham estacas de boa qualidade na épo. ca de novo plantio na várzea, evitando 0 armazenamento de estacas de maio até agosto, como é feito normalmente;

2. $O$ uso de camalhōes mais altos na base de $40-50 \mathrm{~cm}$;

3. Uso de áreas levemente inclinadas, que sofreram novos depósitos de sedimentos pelas enchentes e um pouco areno. sas, de modo a facilitar a drenagem:

4. Evitar plantar mais de uma vez, em quatro anos, no mesmo lugar, usando outras culturas na rotação.

\section{AgRADECIMENTOS}

Agradeço a ajuda de Dr. W. Kerr e da EMATER na coleção de germoplasma e Joāo Batista Moreira pela ajuda técnica. Também agradeço a cooperação de Expedito Ubirajara Peixoto Galvão da UEPAE com experimento 3

\section{SUMMARY}

Over 150 varieties of cassava have been collected from indians and small holders during the last 3 years. Initial experiments already have identified some with interesting characteristics.

1 - A yellow variety (IM 171) with $3,2 \mathrm{mg}$ carotenoids $/ 100 \mathrm{~g}$ of root.

2 - IM 097 capable of yielding more than $5 \mathrm{~kg}$ of $\mathrm{root} / \mathrm{m}^{2} /$ year when well fertilized on a yellow Latosol.

3 - IM 159 capable of yielding $7 \mathrm{~kg}$ of $\mathrm{root} / \mathrm{m}^{2}$ in only 7 months on the fertile varzea.

4 - IM 176 with some tolerance to Root Rot (Phy. tophthora drechsleri).

\section{REFERENCIAS BIBLIOGRAFICAS}

FIGUEIREDO, M.M. \& ALBUQUERQLiE, F.C.

1970 - Podridão mole de raizes de mandioca Pesq. Agropec. Bras., $5: 389-393$.

LOPES, E.B.; MATIAS, E.C.; AGUIAR FILHO, S.P.

1978 - Podridão de raizes de mandioca. Pesq. Agropec. Bras., $13: 45-50$.

LOZANO, J.C. \& BOOTH, R.H.

1978 - Diseases of cassava. In: Cassava Produc. tion Course. Book I, CIAT. P. 145-194.

LOZANO, J.C.; TORO, J.C.; CASTRO, A.; BELLOTTI, A.C.

1978 - Cassava "Seed" quality, sanitary conditions and storage. IN: Cassava Production Course. Book I, CIAT. p. $72 \cdot 83$.

TORO, J.C.: CASTRO, A.; CELIS, E.

1978 - Selection and preparation of Cassava planting material. In: Cassava Production Course. Book I, CIAT. p. 103-107.

(Aceito para publicaçāo em 02-07-80) 